\title{
Discurso e Cotidiano Uma Proposta de Escuta Sobre a "Marcha da Produção"
}

\author{
Roselaine Bolognesi ${ }^{1}$ \\ Ana Maria C. de Almeida²
}

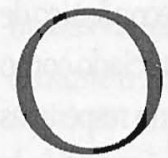

período que compreende o Governo de Juscelino Kubitschek (1956-1960) permanece na memória nacional como os Anos Dourados, do NacionalDesenvolvimentismo, ${ }^{3}$ da consolidação da Democracia, do crescimento econômico e da multiplicação dos signos da modernidade. Segundo a análise de Velloso, a ideologia dos Anos Dourados construiu-se alicerçada no clima de euforia que existia na época. ${ }^{4} 0$ Fim do Estado Novo, a emergência do teatro de revista, o surgimento das rádios, da TV, a multiplicação dos jornais, dos leitores, entre outros, constituíram a representação mais aparente do slogan consagrado por JK: " 50 anos em 5 ", a busca do tempo perdido, cuja grande metaera o desenvolvimento econômico, crescer para depois repartir. 0 espírito ufanista que prevalece na época silencia os conflitos e acentua a união de forças. Partidos políticos, sindicatos e imprensa cerram fileiras em torno do projeto NacionalDesenvolvimentista que tem no ISEB $\mathrm{B}^{5}$ uma de suas fontes inspiradoras.

Assim, é possível afirmar que os anos de 1950 entraram na memória política brasileira como uma década de transformações políticas, econômicas, ideológicas e culturais aceleradas. A transição do mundo rural (passado) para o mundo da atividade

1 Mestranda em Ciências Sociais na Universidade Estadual de Londrina.

2 Professora do Depto. de Ciências Sociais/UEL.

3 Conforme ressalta Benevides, M.V. A esperança como fator de desenvolvimento. In: Gomes, A.C. (ORG.). O Brasil de $J K$. Rio de Janeiro: Editora FGV, 2002, pp. 20-38, antes falava-se em "fomento" e em "fomentar 0 desenvolvimento", tinha-se o esboço de uma proposta de desenvolvimento nacional que ganha fôlego e promete se concretizar nos anos JK. E, na memória coletiva, esse período consagra-se e passa a ser identificado com a expressão Anos Dourados.

4 Velloso, M.P. A dupla face de Jano: romantismo e populismo. In: Gomes, A.C. (org.). Op. cit.

5 Instituto Superior de Estudos Brasileiros - criado em julho de 1955 como órgão do Ministério da Educação e Cultura, constituindo-se em um dos núcleos mais importantes da elaboração da ideologia Nacionaldesenvolvimentista que marcou a política brasileira desde a morte de Getúlio Vargas (1954) até a queda de João Goulard (1964). 
industrial (futuro) pode ser considerada a encruzilhada histórica que motivou a emergência de uma atitude política e ideológica capaz de mobilizar a nação e os mais variados setores da sociedade em torno da construção de um país moderno.

Muitas são as interpretações sobre o período JK, o seu programa de governo ou, mesmo, suafigura pessoal. Sua trajetória política, em muitos casos, confunde-se com os traços de sua biografia e com a história política democrática do país. JKéo homem que constrói a cidade de Brasilia - nova capital do país - com o objetivo de mostrar que o Brasil é uma promessa que podiase realizar. 0 que se mantém na memória sobre este períodoé a resistência das instituições políticas democráticas, melhor dizendo, a permanência e funcionamento dos mecanismos eleitorais, a atuação dos partidos e do Congresso, o Judiciário e o papel do Executivo. Em geral, as mensagens do então presidente Juscelino Kubitschek ao povo brasileiro destacavam a harmonia entre Legislativo e Executivo, articulada às conquistas do seu projeto econômico de modernização para o país, conhecido como Plano de Metas. Esse Plano foi anunciado como programa de governo, 50 anos de progresso em 5 anos de realizações, com pleno respeito às instituições democráticas. Comopartedeseu ideal desenvolvimentista, o programa foi consolidado num conjunto de 30 objetivos a serem alcançados em diversos setores da economia. Na última hora, o plano incluiu mais uma meta, $31^{a}$, chamada de meta-síntese: a construção de Brasîlia. ${ }^{6}$

Benevides ressalta a marca de JK na construção da crença do Brasil como o "país do futuro", a consolidação entre dois brasis - o rural e o industrial -, a intervenção do Estado e a "sedução da tutela", conjunção entre liberdades públicas e desenvolvimentismo. ${ }^{7}$ Segundo Skidmore, a estratégia de JK merece o rótulo de "nacionalismo desenvolvimentista" e não apenas desenvolvimentismo, pela fórmula como foi apresentada ao povo brasileiro, ou seja, como propósitos e ações do governo reforçados por um apelo ao senso do nacionalismo ${ }^{8} \mathrm{Adefesa}$ de que a solução para o subdesenvolvimento nacional, com todas as suas injustiças sociais e tensões políticas, deveriaser a industrialização urgente. 0 autor refere-se ao período juscelinista comoAnosde Confiança (1956-1960) e, assim como Benevides, destaca as realizações econômicas (os 50 anos em 5) e o equilíbrio político como suas principais características. Kubitschek esforçou-se por gerar um senso de confiança entre os brasileiros, escolhendo a nova capital do país como o seu grande símbolo.

Nessa mesma linha, Cardoso identifica os principais recursos utilizados por JK na construção da ideologia desenvolvimentista, enfatizando a modernização econômica como um dos recursos principais de fomento dessa ideologia. ${ }^{9}$ A temática do discurso de

6 Dados extraídos do arquivo CPDoc disponibilizados na internet: www.cpdoc.fgv.br/nav_JK/obrasildejk.

7 Idem.

8 Skidmore, T. Brasil:de Getúlio a Castelo Branco. Rio de Janeiro: Paz e Terra., 1976.

9 Cardoso, M.L. Ideologia do Desenvolvimento Brasil: JK-JQ. Rio de Janeiro: Paz e Terra, 1978. 
Kubitschek se concentra em torno do desenvolvimento com a pretensão de propor uma política que permitisse deflagrar a aceleração do processo de crescimento econômico, superando o estado de atraso e alcançando prosperidade. Através de análise dos discursos de JK, essa mesma autora ressalta que a ênfase do presidente era em torno de uma prosperidade, que poderia ser conseguida através da industrialização. ${ }^{10}$

Entretanto, no plano objetivo, ao mesmo tempo que se vislumbram possibilidades de ritmo acelerado de desenvolvimento urbano-industrial, alguns setores da elite agrária nacional, a exemplo dos grandes produtores de café da região norte do Paraná, se manifestam contrariamente à política econômica cafeeira posta em prática por JK. Essa insatisfação resulta, em 1958, em movimento denominado "Marcha da Produção", acontecimento político com repercussões nacionais e que constitui, no presente, fonte de nossas reflexões. Amplamente divulgada e noticiada pelo jornal Folha de Londrina durante 0 ano de 1958, A Marcha da Produção,

... a princípio como parte de um conjunto de fatos do cotidiano da vida londrinense - no ano de 1958 -, aos poucos vai tomando proporções de um acontecimento político de repercussão nacional, já que se coloca contra o Governo JK e sua política econômica. Um movimento que, ao programar uma grande manifestação marchar em carreata até o Catete para entregar ao Presidente um conjunto de reivindicações dos cafeicultores do Norte do Paraná -, revela uma força política, até então inimaginável, dos "lavradores" da região (era assim que se autodenominavam) contra a política econômica cafeeira, adotada pelo governo brasileiro, especialmente diante da instabilidade de preços do mercado internacional e de acordos bilaterais e multilaterais que o país vinha firmando com organizações internacionais e outros países produtores e consumidores de café. ${ }^{11}$

Ancorados na conclamada "vocação agrícola do país", os cafeicultores exigiam maior proteção aos seus interesses, especialmente uma política mais favorável de subsídios e mudanças nas taxas de câmbio, a fim de favorecer as exportações e a competitividade do café brasileiro no mercado mundial.

Ao noticiar fatos e dar voz aos agentes e políticos da região envolvidos no debate sobre essas questões, o jornal Folh a de Londrina vai prefigurando discursivamente o acontecimento,

${ }^{10}$ Para maior aprofundamento sobre os anos do governo JK indicamos: BoJUNGA, C. JK: o artista do impossivel. Rio de Janeiro: Objetiva, 2001; SiIn, A.M. A política externa no cenário da Guerra Fria. In: os anos de JK. Site do CPDoc http://www.cpdoc.fov.br.: Heliodoro, A.JKexemplo e desafio. Brasília: Thesaurus, 1991.

1 Ceśrio, A.C.C. Projeto de Pesquisa: Os sentidos da Marcha da produção: 0 acontecimento no texto do jornal, UEL, 2003. p.1. 
conferindo-lhe sentido, projeção, e uma clara identificação com os interesses dos cafeicultores. Por isso, pode-se afirmar que a "Marcha da Produção" jáestava sendo gestada muito antes do dia 18de outubro de 1958, data marcada para a saída da carreata, da cidade de Maringáe que deveriaser engrossada pelos manifestantes de Londrina, de outras cidades do Norte do Paraná, deSão Paulo demais Estados produtores de caféda Federação.

Na realidade, esse acontecimento, ao mesmo tempo que está cercado pelos sentidos da vida cotidiana local e regional (a acentuação dos valores de progresso e de riqueza, via cafeicultura, tão presentes na região desde a sua colonização pela Companhia de Terras Norte do Paraná-CTNP), expressa interesses econômicos de associações de classes, interesses partidários e de uma elite política local e regional que tenta se afirmar através de um discurso do tipo liberal capitalista: “... percebe-se um discurso fortemente marcado por uma formação ideológica burguesa do tipo liberal capitalista através do qual os cafeicultores e os que lhes davam apoio se insurgiam contra o Estado intervencionista, clamando por liberdade de iniciativa econômica e, ao mesmo tempo, reivindicando protecionismo". 12

Assim, análises sobre o jornal constitui em via importante para a compreensão das várias formações discursivas (política cafeeira/associações de classe político-partidárias, entre outras), que recobrem este acontecimento. Dentre as várias abordagens teóricometodológicas, a Análise de Discurso, de linha francesa e inspirada em Michel Pêcheux, bem como discussões sociológicas sobre cotidiano constituem nossas principais fontes de reflexão. Como disciplina de entremeio, a Análise de Discurso instaura uma nova possibilidade de se pensar o discurso como objeto de pesquisa nas Ciências Sociais. Em outras palavras, permite a apreensão do discurso como expressão do real, espaço em que emergem as significações e a ideologia, consideradas como partes integrantes das práticas sociais dos sujeitos em suas relações com o mundo. Como uma construção social, um empreendimento coletivo e interativo por meio do qual as pessoas - na dinâmica das relações sociais historicamente datadas e culturalmente localizadas - constroem as significações a partir das quais lidam com as situações e fenômenos que vivenciam.

Esse referencial teórico torna possível uma apreensão acerca do acontecimento Marcha da Produção e também dos rumores, das falas, dos dizeres cotidianos construídos paralelamente ao acontecimento, significando-o e produzindo efeitos de sentido acerca do mesmo, seja privilegiando a fala das lideranças do movimento, seja dando destaque aos fatos cotidianos da cidade de Londrina tal como aparecem no jornal. Esta é uma 
proposta que pensa ser possível aliar discurso e cotidiano, tendo em vista que coloca em evidência discussões que permitem partir

(...) das contingências e banalidades do cotidiano para chegar a um mundo de significações, através de mediações entre o particular e o global, o individual e o coletivo, o subjetivo e o objetivo. 0 mundo (vivido) (...) parece desvendar-se num espectro de culturas e identidades, a partir do momento em que é sociologicamente problematizado (concebido). 0 sociólogo debate-se com o desafio de desvendar 0 social através das imediaticidades do quotidiano. E isso depende dos questionamentos sociológicos que faz, capazes ou não de recapturarem o social na sua aparente facticidade que é dada pelos traços epidérmicos da quotidianidade. ${ }^{13}$

Considera-se, portanto, que partir do discurso cotidiano, no caso do jornal Folha de Londrina, significa, também, considerar que o seu estudo pode levar-nos à compreensão de conflitos da sociedade nessa ou em outras épocas. Pois, conforme afirma Henry Lefebvre, a vida cotidiana é o lugar em que se formulam os problemas concretos da produção em sentido amplo: a maneira como é produzida a existência social dos seres humanos. ${ }^{14}$ Sendo assim, os fatos cotidianos são dignos de conhecimento e ponto de partida para compreender a complexidade das relações sociais e os aspectos subjetivos e objetivos que as revestem. Os empregos do tempo, as banalidades, os anúncios de jornais e outros, constituem, portanto, fatos cotidianos importantes para o conhecimento sociológico. 0 desafio está justamente em reconduzir fatos aparentemente insignificantes ao conhecimento e reagrupá-los, não arbitrariamente, mas segundo conceitos e teorias capazes de captar 0 aparentemente insignificante e compreender o sentido.

Tratar o cotidiano trata-se, portanto, de caracterizar a sociedade em que vivemos, que gera a cotidianidade (e a modernidade). Trata-se de defini-la, de definir suas transformações e suas perspectivas, retendo entre os fatos aparentemente insignificantes, alguma coisa de essencial, e ordenando os fatos, Não apenas a cotidianidade é um conceito, como ainda podemos tomar esse conceito como fio condutor para conhecer a "sociedade", situando o cotidiano no global: o Estado, a técnica e a tecnicidade, a cultura (ou a decomposição da cultura) etc. Eis, a nosso ver, a melhor maneira de tratar a questão, o procedimento mais racional para captar a sociedade, penetrá-la e defini-la. ${ }^{15}$

\footnotetext{
${ }_{13}$ PAIs, J.M. Vida Cotidiana: enigmas e revelações. São Paulo: Cortez, 2003. p.20.

${ }^{14}$ Lefebvre, H. A vida cotidiana no mundo moderno. São Paulo: Ática, 1991.

15 Idem, p. 35.
} 
Assim é que a heterogeneidade, as contradições, a dinâmica, as ideologias, os discursos e outros, podem ser aspectos importantes a serem considerados. São conceitos que devem ser compreendidos em relação aos processos sociais mais gerais e mais singulares da vida social, nos momentos ativos do uso da linguagem, os contextos em que se inscrevem, considerando que compreender a produção de sentidos cotidianos implica considerar sua relação com as instituições, o ideológico, o político e o simbólico. Por isso, consideramos que a Análise de Discurso, como teoria e método, intervém de forma pertinente e reveladora para análises do cotidiano londrinense nos anos de 1950, década em que o movimento Marcha da Produção é constituído.

\section{A AnÁlise de Discurso: UM DIÁlOGO POSSÍVEL COM AS CIÊNCIAS SOCIAIS}

A Análise de Discurso, influenciada por Michel Pêcheux, surgiu nos anos 1960, colocando em relação o campo da língua e o campo da sociedade apreendido pela história. Conforme Pêcheux, o quadro epistemológico de análise do discurso consiste na articulação de três regiões do conhecimento: o materialismo histórico (como teoria das formações sociais e de suas transformações, compreendida aí a teoria das ideologias); a lingüística (como teoria dos mecanismos sintáticos e dos processos de enunciação ao mesmo tempo); e a teoria do discurso (como teoria da determinação histórica dos processos semânticos). ${ }^{16}$

AAnálise de Discurso tem como objetivo compreender como a língua faz sentido, e como ela se relaciona com o simbólico e com o trabalho social geral, constituindo 0 homem e sua história. Considerando a língua, portanto, como mediação necessária entre o homem e sua realidade natural e social. Como propõe Orlandi,

Em uma proposta em que o político e o simbólico se confrontam, essa nova forma de conhecimento coloca questões para a Lingüística, interpelando-a pela historicidade que ela apaga, do mesmo modo que coloca questões para as Ciências Sociais, interrogando a transparência da linguagem sobre a qual se assentam. Dessa maneira, os estudos discursivos visam pensar o sentido dimensionado no tempo e no espaço das práticas do homem, descentrando a noção de sujeito e relativizando a autonomia do objeto da Lingüística. ${ }^{17}$

\footnotetext{
${ }^{16}$ Soto, W.G. A análise do Discurso nas Ciências Sociais. In: Cadernos de Sociologia. Vol.9, Porto Alegre, 1998. pp. 161-187.

17 ORLand, E.P.Análise de Discurso: princípios e procedimentos. Campinas: Pontes, 2000 p.16.
} 
Constituindo-se em espaço de questões criadas pela relação entre três domínios disciplinares (Lingüística, Marxismo e Psicanálise), a Análise de Discurso ressalta a não separação entre forma e conteúdo, ou seja, procura compreender a língua não só como estrutura, mas, sobretudo, como acontecimento. Assim, ao reunir estrutura e acontecimento, a Análise de Discurso pressupõe a forma material como acontecimento do significante (língua) e um sujeito afetado pela história. Ela desloca, pela contribuição da Psicanálise, a noção de homem para a de sujeito, sendo este constituído na relação com o simbólico, na história. Como herdeira dessas três regiões do conhecimento, podese considerar que a noção de discurso não se reduz a nenhum desses campos, mas está na confluência de todos eles, ou melhor, interroga a Lingüística pela historicidade, questiona o Materialismo perguntando pelo simbólico e se demarca da Psicanálise pelo modo como, considerando a historicidade, trabalha a ideologia como materialmente relacionada ao inconsciente sem ser absorvida por ele. ${ }^{18}$ Dessa forma, épossível considerar que a Análise de Discurso constitui o espaço em que a Lingüística tem a ver com a Filosofia e com as Ciências Sociais. Na perspectiva discursiva, a linguagem só se constitui como tal porque faz sentido e só faz sentido porque se inscreve na história. 0 que interessa para a Análise de Discurso é o texto, mas o texto como "... a unidade que o analista tem diante de si e da qual ele parte. 0 que faz diante de um texto? Ele remete imediatamente a um discurso que, por sua vez, se explicita em suas regularidades pela sua referência a uma ou outra formação discursiva que, por sua vez, ganha sentido porque deriva do jogo definido pela formação ideológica dominante naquela conjuntura". 19

0 texto, então, é considerado como via de acesso ao discurso. É unidade complexa de significação, uma vez que organiza a relação da língua com a história e com o sujeito, em sua relação com o mundo. 0 texto possibilita perceber a exterioridade a partir dos elementos que internamente o compõem. Recorrer à historicidade, neste caso, significa compreender como, num determinado momento, numa determinada época, se produziram determinados efeitos de sentidos e como estes interferiram na constituição desse discurso, que, por sua vez, tem relação com a materialidade histórica e social. Ou seja, com um conjunto de relações sociais, um modo de produção, ideologias e outros. De acordo com essa teoria interpretativa, a intenção é conectar o particular ao todo, sem perder de vista suas relações e especificidades.

\footnotetext{
${ }^{18}$ Essa discussão da Psicanálise (inconsciente), não é aqui aprofundada. Mas, cabe ressaltar que essa noção de inconsciente é de Freud, recuperado por Lacan e definida, de forma simplificada na Análise de Discurso, como o discurso do outro.

19 Idem, p. 63.
} 
Segundo Pêcheux, a relação imaginária dos indivíduos com suas condições reais de existência não são homogêneas, pois dependem do momento histórico específico e da maneira como as "formas ideológicas", em presença, cumprem seu papel dialético de matéria-prima e de obstáculo em relação à produção de conhecimentos. ${ }^{20}$ Para esse autor, o discurso não pode ser compreendido fora de uma relação ideológica de classes, ou melhor, desvinculado das condições materiais da qual emerge. Isso justifica o fato de que, para a Análise de Discurso, o discurso éum processo que se desenvolve de múltiplas formas e em determinadas situações sociais como efeito de sentido construído no processo de interlocução. E mais, o discurso nãoéfechado em si mesmo e nem éde domínio exclusivo do locutor, afinal, o que se diz significa em relação ao que não se diz, ao lugar social do qual se diz, para quem se diz e em relação a outros discursos. 0 locutor assume uma função social na medida em que está impregnado pela exterioridade, pelo contexto histórico-social. Afinal, as condições de produção interferem na constituição do discurso.

Sendo assim, Orlandi considera que o discurso se caracteriza pelo movimento dos sentidos, errância dos sujeitos, lugares provisórios de conjunção e dispersão, de unidade e de diversidade, de indistinção, de incerteza, de trajetos, de ancoragem e de vestígios. ${ }^{21}$ Para essa autora, isso éconsiderado como o ritual da palavra, mesmo as que não são ditas. De um lado, éna movência, na provisoriedade, que os sujeitos e os sentidos se estabelecem; de outro, eles se estabilizam, se cristalizam, permanecem. 0 que significa dizer que os sentidos não estão soltos, são sempre "administrados". Não há neutralidade nem mesmo no uso mais aparente e cotidiano dos signos.

Dessa maneira, recorrer à Análise de Discurso, em análises sociológicas que tomam textos como objeto empírico de análise, parece pertinente, uma vez que esta se propõe a mostrar o funcionamento dos mesmos, observando sua articulação com as formações ideológicas. AAnálise de Discurso, portanto, pode assumir uma posição-chave, um ponto de articulação entre a realidade descrita, os mecanismos da fala, a ideologia e o silêncio. A Análise de Discurso pode ser uma possibilidade de considerar os fatos e acontecimentos cotidianos - tal como aparecem no jornal - como textos, ou seja, uma via de acesso aos discursos que lhe correspondem, penetrando, assim, na complexidade das questões em que se inscrevem. Vale ressaltar que o termo Formação Ideológica é aqui empregado tal como o define Brandão, ou melhor, como sendo "... constituída por um conjunto complexo de atitudes e representações que não são nem individuais, nem universais, mas dizem respeito, mais ou menos diretamente, às posições de classe em conflito umas com as

${ }^{20}$ PECheux, M. Semântica e Discurso: uma crítica à afirmação do óbvio. Campinas: Editora da UnicasP, 1995, p.77.

${ }^{21}$ Orundi, E. P. Op. Cit., 2000. 
outras. Cada formação ideológica pode compreender várias formações discursivas interligadas" ${ }^{22}$

Entende-se, assim, que uma formação ideológica tem, necessariamente como um de seus componentes, uma ou várias formações discursivas interligadas. Significa que os discursos são governados por formações ideológicas. Torna-se evidente que o papel que a formação discursiva assume é o de definir o que pode e deve ser dito a partir de uma posição dada em uma conjuntura dada. Desse modo, a noção de Formação Discursiva ${ }^{23}$ concebida por Foucault e discutida por Pêcheux representa, na Análise de Discurso, um lugar central de compreensão da articulação entre língua e discurso.

Ao se inscrever nas formações discursivas existentes, o indivíduo tem contato com ideologias diversas e passa a significar e atribuir sentido ao mundo conforme a especificidade do processo de interpelação ideológico pelo qual passou e passa. Por isso, é possível que um mesmo enunciado signifique de formas diferenciadas, afinal, os sentidos produzidos são diferentes de acordo com as posições discursivas em que se inscrevem. AAnálise de Discurso, portanto, considera linguagem, pensamento, realidade, historicidade, discurso e ideologia como dimensões que se complementam e tornam possível o ato de significar, de nos reconhecermos na condição de sujeito no mundo, e de atribuirmos sentidos a ele.

Influenciado por Althusser, ${ }^{24}$ Pêcheux compartilhou com ele a idéia de que 0 indivíduo é interpelado em sujeito pela Ideologia. Portanto, Pêcheux rompe com uma concepção idealista do sujeito, ou melhor, deste como sendo a origem do discurso e plenamente consciente do que diz. Afinal, uma vez interpelado como sujeito, este se esquece das determinações que o constituíram enquanto tal e que o colocaram no lugar que ele ocupa. Nesse sentido, a Análise de Discurso, tenta desmistificar a evidência do sujeito e, consequientemente, dos sentidos, uma vez que este é suporte de significações. Pêcheux busca a materialidade do discurso e do sentido, uma "forma-sujeito" - definida por Althusser como forma de existência histórica do indivíduo -, uma noção não subjetivista da subjetividade. ${ }^{25}$

22 BRANDĩo, H.N. Introdução à Análise do Discurso. Campinas: Editora da Unıcamp, 1995. p. 90.

${ }^{23}$ Esse conceito refere-se ao conjunto de enunciados marcados pelas mesmas regularidades, pelas mesmas "regras de formação". A formação discursiva define-se por sua relação com a formação ideológica, isto é, os textos que fazem parte da formação discursiva remetem a uma mesma formação ideológica. A formação discursiva determina o que pode e deve ser dito a partir de um lugar social historicamente determinado. Um mesmo texto pode aparecer em formações discursivas diferentes, acarretando, com isso, variações de sentidos. Ver FoucAult, M. Arqueologia do Saber. Rio de Janeiro: Forense Universitária, 2002.

${ }^{24}$ AtThusser, L. Aparelhos Ideológicos de Estado: nota sobre os aparelhos. Rio de Janeiro: Graal, 1983.

${ }^{25}$ PêCHeux, M. Op. Cit., 1995. p.133. 
Sendo assim, o discurso comporta duas formas de esquecimento: 1) o da ordem da enunciação, pois ao falarmos fazemos de uma maneira e não de outra, indicando que 0 dizer sempre poderia ser outro (isso significa em nosso dizer e nem sempre temos consciência disso) - esse esquecimento produz em nós a impressão da realidade do pensamento; e 2) esquecimento ideológico, queé da instância do inconsciente e resulta do modo pelo qual somos afetados pela Ideologia - produz a ilusão de que somos a origem do que dizemos quando, na verdade, apenas retomamos sentidos preexistentes. $\mathrm{E}$ isso tem a ver com a maneira como nos inscrevemos na língua e na história, com o lugar/ posição que ocupamos na sociedade no momento da interlocução.

Orlandi, ao avançar nessa discussão, ressaltou que os dizeres não são propriedades particulares. As palavras não são só nossas. Estas significam pela história e pela língua. 0 que édito em outro lugar também significa nas nossas palavras. O sujeito diz, pensa que sabe o que diz, mas não tem acesso, nem controle sobre o modo pelo qual os sentidos se constituem nele. Assim, para compreender o funcionamento do discurso é fundamental compreender a sua relação com os sujeitos e com a ideologia. É nesse sentido que Orlandi afirma que

Os dizeres não são, como dissemos, apenas mensagens a serem decodificadas. São efeitos de sentidos que são produzidos em condições determinadas e que estão de alguma forma presentes no modo como se diz, deixando vestígios que o analista do discurso tem de apreender. São pistas que ele aprende a seguir para compreender os sentidos aí produzidos, pondo em relação o dizer e sua exterioridade, suas condições de produção. Esses sentidos têm a ver com o que é dito ali mas também em outros lugares, assim como com o que não é dito, e com o que poderia ser dito e não foi. Desse modo, as margens do dizer, do texto, também fazem parte dele. ${ }^{26}$

Esta abordagem teórica de alguns aspectos da Análise de Discurso teve a intenção de pensar a língua em sua materialidade e compreender a necessidade da ideologia na sua relação com a produção de sentidos, uma vez que esta se constitui justamente no encontro da materialidade da língua com a materialidade histórica. Como o discurso (materialidade específica da ideologia) é o lugar desse encontro, é nele que melhor podemos encontrar esse ponto de articulação. Assim é que,

Para Pêcheux, o discurso é efeito de sentido entre locutores. Compreender o que é efeito de sentido é compreender que o sentido não está (alocado) em lugar nenhum mas se produz nas relações: dos sujeitos, dos sentidos, e isso só é possivel, já que o sujeito e o

${ }^{26}$ ORLAnd, E. P. Op. Cit., 2000. p.30. 
sentido se constituem mutuamente, pela inscrição no jogo das múltiplas formações discursivas (que constituem as distintas regiões do dizível para os sujeitos). As formações discursivas são diferentes regiões que recortam o interdiscurso (o dizível, a memória do dizer) e que refletem as diferenças ideológicas, o modo como as posições dos sujeitos, seus lugares sociais aí representados, constituem sentidos diferentes .... ${ }^{27}$

Retomar as condições de produção de um discurso significa retomar as formações discursivas nas quais os textos se inserem, tentando compreender as relações com as formações ideológicas que lhe correspondem; é compreender o processo de produção de sentidos de uma situação de interlocução específica e constituída na história enquanto efeito no processo de interação - autor/leitor. Vale ressaltar que todo discurso se estabelece na relação com um discurso anterior e aponta para outro. Não há discurso fechado em si mesmo, mas um processo discursivo sempre em movimento. 0 discurso variavelmente aponta para outros, é marcado pela incompletude e pelo silêncio.

\section{O Silêncio Como Parte Constitutiva do Discurso}

Na tentativa de compreender como o discurso produz sentidos é preciso considerar 0 "silêncio" e, de acordo com a Análise de Discurso, para compreender o silêncio, épreciso considerar a historicidade, ou melhor, o texto como discurso, o trabalho dos sentidos contidos nele, assim como os processos de construção de efeitos de sentidos. 0 que significa apelar para a interdiscursividade, trabalhando entremeios, reflexos indiretos, pois o silêncio não é transparente, não fala, ele significa. É preciso considerar o silêncio a partir da relação fundamental com o não dizer, afinal, "Se a linguagem implica silêncio, este, por sua vez é o não dito visto do interior da linguagem, não é o nada, não é o vazio sem história. É silêncio significante (...) o silêncio é a garantia do movimento de sentidos. Sempre se diz a partir do silêncio". ${ }^{28}$

Com referência às discussões de Orlandi, entende-se que a relação do homem com o pensamento não édireta, bem como a relação entre linguagem e pensamento, linguagem e mundo tem suas mediações, é multidimensional. ${ }^{29} 0$ texto enquanto espaço simbólico é "bólido de sentidos". Como espaço discursivo possui vários significados, sentidos; ele pode dizer através do silêncio e permitir tantas leituras quantos forem os leitores, ou seja, o "texto é multidirecional".

${ }^{27}$ ORLANDi, E. P. As Formas do Silêncio: no movimento dos sentidos. Campinas: Editora da Unicamp, 1997. p. 20.

${ }^{28}$ Idem, p. 23.

29 ORLANDi, E. P. Interpretação: Autoria, Leitura e Efeitos do Trabalho Simbólico. Rio de Janeiro: Vozes, 1996. 
Dessa perspectiva, o silêncio é considerado como o real do discurso, ou seja, a possibilidade mesma de sua significação. Na multiplicidade, na diversidade, na incompletude e na profundidade, características que marcam sua existência, o silêncio sempre se coloca. Isto significa considerar que 0 homem está condenado a significar. "Tudo tem que fazer sentido"30 $\mathrm{e}$ o homem está irremediavelmente constituído pela sua relação com o simbólico. Sendo assim, o silêncio não fala. 0 silêncio é. Ele significa.

0 silêncio é fugaz. 0 homem não o suporta e assim não lhe permite senão uma existência efêmera, por isso a necessidade da linguagem para torná-lo observável. A fala, nessa perspectiva, divide o silêncio, organiza-o. 0 silêncio édisperso e a fala, por sua vez, é voltada para a unicidade, deixando visíveis e funcionais segmentos que tornam a significação calculável. Para tanto, é preciso considerar sua materialidade histórica, as condições em que ele se produz já que, "... em face do discurso, o sujeito estabelece necessariamente um laço com o silêncio; mesmo que esta relação não se estabeleça em um nível totalmente consciente. Para falar, o sujeito tem necessidade de silêncio, um silêncio que éfundamento necessário ao sentido e que ele reinstaura falando" ${ }^{31}$

É a partir destas considerações que esta autora formula uma distinção entre silêncio fundador e política do silêncio. Se o primeiro - o silêncio fundador - é aquele que existe nas palavras, significa o não dito; o segundo - a política do silêncio/ silenciamento - subdivide-se em: a) silêncio constitutivo (para dizer é necessário não dizer) - todo dizer cala algum sentido e uma palavra apaga necessariamente outras palavras; b) o silêncio local (a censura) - proíbe dizer determinadas coisas em uma dada conjuntura. Trabalhando os limites das formações discursivas, o silêncio determina, consequentemente, os limites do dizer. Silêncio e linguagem, enquanto discurso e interação, são modos de produção social - não são neutros, inocentes e nem naturais -, estão impregnados de intencionalidades, por isso constituem o lugar em que se manifesta a ideologia. Daí que, trabalhar no nível da produção de sentidos, a partir dessa perspectiva, implica em questionar a própria produção de efeitos de sentidos cotidianos de modo a entender a construção social do discurso (ou discursos) em relação ao gesto cotidiano de dar sentido ao mundo, de interpretá-lo. É a possibilidade de apreensão do texto do jornal como objeto empírico e de considerar que a opacidade da língua e a obscuridade dos processos que se realizam no cotidiano podem ser intrigantemente reveladores.

30 Oriand, E. P. Op. Cit., 1997, p. 31.

${ }^{31}$ Idem, p. 71. 


\section{Produção de Sentidos no Cotidiano: Um Lugar de "Escuta"}

Com base nessas discussões, o texto do jornal Folha de Londrina - objeto empírico - constitui o ponto de partidae de acesso ao discurso - objeto teórico. Considera-se o texto do jornal uma unidade complexa de significações com condições próprias de produção. Repleto de historicidade, modo pelo qual produz sentidos, o texto não é transparente e nem uma unidade pronta e acabada, ao contrário, é sua característica constitutiva a incompletude e 0 silêncio.

Presentifica-se, desse modo, apelar para a compreensão das condições e da situação nas quais o acontecimento "Marcha da Produção" foi construído, ou seja, buscar na exterioridade, na formação social concreta, enfim na historicidade os significados do discurso. 0 que significa pensar o discurso como fenômeno social capaz de expressar embates sociais e ideológicos de uma época. Dito de outra forma, significa levar em conta a relação língua e história, língua e sociedade, a língua fazendo sentido enquanto trabalho simbólico, próprio do trabalho social geral. Portanto, fruto da relação com as práticas sociais.

Écom basenessaspremissas que emergecomoessencial, para as reflexões aqui presentes, aliar o dispositivo teórico da Análise de Discurso ao dispositivo analítico das Ciências Sociais (principalmente as análises sobre o cotidiano), admitindo que a compreensão da realidade social não se limita ao plano empírico imediato, avançando pelas relações entre a linguagem e as práticas sociais. Este posicionamento nos leva a uma "outra escuta" sobre a Marcha da Produção, problematizando o cotidiano londrinense da época. Melhor dizendo, enquanto manifestação regional, objetiva-se compreender como este acontecimento, ao ser noticiado e interpretado pelo jornal Folha de Londrina, estava ao mesmo tempo marcado pelos sentidos "ordinários" da vida cotidiana, e produziu efeitos de sentidos acerca do imaginário e do cotidiano de Londrina. Dessa forma, tais pressupostos teóricos permitem-nos esboçar uma perspectiva discursiva acerca da memória de uma época. Segundo Mariani, "... o discurso jornalístico toma parteno processo histórico de seleçãa de acontecimentos que serão recordados no futuro. E mais ainda: uma vez que ao selecionar está engendrando efixando sentido para estes acontecimentos, a imprensa acaba por constituir no discurso um modo (possível) de recordação do passado". 32

${ }^{32}$ Mariani, B. S. C. Os primórdios da imprensa no Brasil (ou: de como o discurso jornalístico constrói memória). In: ORLANDI, E. P. (Org.). Discurso Fundador: a formação do país e a construção da identidade nacional. Campinas: Pontes, 1993. p. 33. 
Nesse sentido, enquanto no cotidiano os homens tecem relações sociais, apropriam/ atribuem valores esignificados, fazem uma leitura sobre fatose acontecimentos, dão evasão às suas vontades individuais, compartilham do senso comum, tornam possível a existência individual e coletiva, no jomal, esses sentidos, além de serem objetos de apropriação e de seleção, são reinterpretados e ressignificados simbolicamente, produzindo e/ou reproduzindo o acontecimento, conseqüentemente contribuindo para a constituição da memória de uma época. Assim, épossivel perceber que oJornal Folha de Londrina, ao noticiar, interpretar, dar voz aos vários atores da "Marcha da Produção" (especialmente seus líderes regionais-políticos ou não - a exemplo do presidente da Associação dos Lavradores do Norte do Paraná, Álvaro Godoi), tomou clara posição de identificação com os interesses dos cafeicultores, dos grupose setores da sociedade que se vinculavam à realização da Marcha.

Para estes, o projeto de desenvolvimento de JK, via industrialização e urbanização feria os interesses agrários, tendo em vista que deslocava da agricultura para a indústria o sentido de progresso e de modernização para o país. Desse modo, ao discurso da modernização pretendida por JK, contrapõe-se o discurso do progresso do Norte do Paraná, atrelado à lavoura cafeeira, instaurando-se o confronto entre a emergência do Brasil urbano e o sedimentado Brasil agrário, o conflito entre as forças tradicionais da cafeicultura e as forças modernas do Brasil urbano-industrial.

Porém, para compreender esses conflitos e contradições presentes na região e especialmente em Londrina, torna-se necessário deslocar a "escuta", problematizando o cotidiano londrinense da época, via jornal, na medida que em suas páginas e em seus textos estão presentes os efeitos de sentidos produzidos por estas questões. Afinal, enquanto a caracterização de "anos dourados" dada a este período configura-se no imaginário nacional ao lado da denominação de "bons tempos", fruto do processo de aceleração da modernização do país, através do desenvolvimento industrial e urbanização, regionalmente, na década de 1950, especialmente no ano de 1958, consolida-se a fase mais dinâmica da cafeicultura (tanto em termos de expansão geográfica quanto em modernização - racionalização e planejamento do uso do solo), atingindo em 1960 a fase de superprodução. ${ }^{33}$ Prevalece na região um imaginário de progresso aliado à cafeicultura atividades agrícolas em geral:

33 Ver: Cancian, N. A Cafeicultura Paranaense 1900/1970. Curitiba: Grafipar, 1981. 
0 Norte do Paraná, nas décadas de 1950 e 1960, vivencia o fim do monopólio político e econômico da Companhia de Terras Norte do Paraná (CTNP). (...) Com 0 aumento do preço do café, e a riqueza provinda desse produto fundamenta-se 0 poder e o controle da cidade pelos cafeicultores. (...) Assim é que, nessa época, configura-se a "nova civilização do café", e a emergência de novas representações sobre Londrina e o Norte do Paraná. A região é caracterizada, agora, como Eldorado Cafeeiro, e cabe aos cafeicultores o papel de pioneiros dessa riqueza e da nova cidade que surge a partir da prosperidade da cafeicultura - a urbanização e a valorização da cidade marcadamente moderna. ${ }^{34}$

Na realidade, todo o Norte do Paraná e especialmente Londrina já vivenciavam os signos da modernidade prevalecentes no país. Londrina é exemplo da cidade moderna e do progresso, consolidada pela imagem de "cidade-jardim". Porém, tal progresso, fruto das riquezas do campo e da conciliação dos interesses das elites agrárias e urbanas. Talvez, por isso, o jornal Folha de Londrina se posicionasse favoravelmente às reivindicações dos cafeicultores, representantes da elite agrária regional, quando apoiou a "Marcha da Produção".

Portanto, a opção pela "escuta" deste acontecimento aliando discurso e cotidiano, representa pensar como esses significados foram compartilhados pelos coadjuvantes do acontecimento, sem, no enfanto, desprezar seus principais atores. Melhor dizendo, enfatizar, tal como entende Martins, aquele homem comum que no pequeno mundo de todos os dias constrói sua existência, faz uma leitura sobre a vida, fatos e acontecimentos, atribuindo valores. ${ }^{35} 0$ que representa aceitar que o homem se depara com um mesmo mundo, mas de maneiras diversas e particulares, sendo capaz de visualizá-lo e significá-lo variavelmente conforme as experiências do dia-a-dia.

Mais ainda, esta outra "escuta", significa ouvir o "silêncio" de muitas vozes e compreender a sua complexidade, perceber que, no cotidiano, os homens estão envolvidos num amplo e complexo movimento que muitas vezes não é visível; no entanto éo que dá sentido às vivências e experiências locais. Nessa medida, considera-se que na história local e cotidiana estão as circunstâncias da história, essa "história circunstancial", ou

\footnotetext{
${ }^{34}$ Lıм^, G. C. D. de. As Hesitações do Moderno: silêncio e conflito na fala de uma liderança regional. Monografia de Conclusão do Bacharelado em Ciências Sociais. Departamento de Ciências Sociais, UEL/Londrina, 2004. p. 24. Outros estudos sobre a região e suas representações merecem destaque: Adum, S. M. S. L. Imagens do Progresso: civilização e barbárie em Londrina. 1930/1960. Dissertação de mestrado. Departamento de História, Unesp/ Assis, 1991; Arias NETo, J. M. O Eldorado: representações da política em Londrina. 1930/1975. Londrina: Eduel, 1998; ALMEIDA, A.M. C. A Morada do Vale: sociabilidade e representações (um estudo sobre as famílias pioneiras do Heimtal). Londrina: Eduet, 1997.

${ }^{35}$ Ver: MarTins, J.S. A sociabilidade do homem simples: cotidiano e história na modernidade anômala. São Paulo: Hucitec, 2000.
} 
seja, marcada pela junção de fragmentos da circunstância e cujo sentido é atribuído ou ditado pela história. Essa história local não tem a mesma escala de tempo dos grandes processos históricos, por isso mesmo seus agentes e personagens não podem captar imediatamente o significado histórico de suas ações, de seu trabalho e, até, de suas lutas. Nem imediatamente, nem diretamente..$^{36}$

Assim, ao analisar o Jornal Folha de Londrina, énecessário buscar como referência, além das falas dos líderes da "Marcha da Produção", outras colunas, notícias, a fim de compreender o cotidiano da cidadee região naépoca, o que representa descobrir as outras vozes também presentes e/ou silenciadas, mas que "significam" por outras vias e processos. Representa ter como referência o olhar do "insignificante" em relação à história que se desenrola apesar dele e ao redor dele, ou seja, aquele também protagonista e significante, porém ausente e invisível, porque não envolvido diretamente no e com o acontecimento.

Afinal, consideramos, tal como Martins, que o significante ganha corpo na "circunstância", que os grandes acontecimentos e processos históricos só são significativos na medida que são vivenciados e interpretados pelo "homem simples" ${ }^{37}$ № âmbito da circunstância, do local,é que os grandes acontecimentos ganham sentido e são re-significados variavelmente conforme aqueles que o interpretam. 0 que implica em compreender o processo histórico por uma outra perspectiva, enfatizando a heterogeneidade complexidade do cotidiano, tomando o texto do jornal como ponto de partida para a compreensão das contradições e conflitos presentes no dia-a-dia, bem como as significações estabilizadas de um contexto histórico, viadominação ideológica. Enfim, procurarentender como este cotidiano estáenvolvido por uma formação discursiva que, por sua vez, está atravessada por outras formações discursivas e se inscreve no interior de uma formação ideológica.

Dessa forma, esta aproximação das discussões da Análise de Discurso com as análises sociológicas sobre o cotidiano representa aceitar que estamos trabalhando com o simbólico, ou seja, considerar que as práticas discursivas são práticas simbólicas, que a relação língua e sociedade não é transparente, assim como a relação homem e mundo também não é direta, está atravessada por significações, pela linguagem. Brandão salienta que, "Como elemento de mediação necessária entre homem e a realidade e como forma de engajá-lo na própria realidade, a linguagem é o lugar do conflito, de confronto

${ }^{36}$ Para um aprofundamento dessa discussão sobre o silêncio enquanto fundamental na linguagem e na constituição do sujeito consultar: ORLANDı, E. P. As formas do silêncio: nos movimentos dos sentidos. Campinas: Editora da Unicamp, 1997; MARTins, José DE S. Subúrbio. Vida cotidiana e história no subúrbio da cidade de São Paulo: São Caetano, do fim do Império ao fim da República Velha. São Paulo: Hucitec; São Caetano do Sul: Prefeitura de São Caetano do Sul, 1992.

${ }^{37}$ Idem. 
ideológico, não podendo ser estudada fora da sociedade uma vez que os processos que a constituem são histórico-sociais. Seu estudo não pode estar desvinculado de suas condições de produção". 38

Assim, para a Análise de Discurso, as práticas discursivas são práticas simbólicas, portanto, práticas sociais, produzidas nas relações sociais cotidianas. 0 discurso, enquanto prática simbólica, tem na materialidade lingüística a expressão dos conflitos, das contradições próprias das relações sociais inscritas na história. Por isso, se a língua, no caso o Jornal Folha de Londrina, constitui a materialidade do discurso, e os processos discursivos são a fonte da produção de sentidos entre interlocutores, faz-se necessário analisar como o discurso materializado na língua reflete as especificidades de uma formação social e também as circunstâncias históricas nas quais se inscreveu a "Marcha da Produção". Como propõe Pêcheux, "Diremos que as contradições ideológicas que se desenvolvem através da unidade da língua são constituídas pelas relações contraditórias que mantém, necessariamente entre si os 'processos discursivos', na medida em que se inscrevem em relações ideológicas de classes". 39

Portanto, a interpretação da "Marcha da Produção", à luz dessas premissas, pode apreender o caráter de manutenção ou de subversão da dominação ideológica, expressão dos embates políticos e sociais da base material da sociedade. Melhor dizendo, propõe entender que este acontecimento constitui expressão das contradições ideológicas de classes e das relações de poder, que estão inscritas na ordem do discurso e controladas, no cotidiano, por determinados grupos. Afinal, existe uma luta pela administração dos sentidos e pelo que pode ser dito, e as palavras só possuem significados na medida em que são ditas por alguém em circunstâncias e posição específicas, lembrando a questão da autoridade do dizer, de acordo com as abordagens de Foucault tem suas discussões sobre saber e poder. ${ }^{40} \mathrm{E}$ preciso, porém, pensar nas outras interpretações que conferem outros sentidos aos acontecimentos, ou seja, por meio de uma "escuta" de outras vozes ou mesmo pelo silenciamento, na medida que sempre há conflitos e disputas para o estabelecimento do predomínio de uma interpretação, de um sentido e não outro, agindo sobre a memória do dizer.

\footnotetext{
38 Brandĩo, H. N. Op. Cit., 1995, p.12.

39 PÉcheux, M. Semântica e Discurso: uma crítica à afirmação do óbvio. Campinas: Editora da Unicump, 1994. p.93.

${ }^{40}$ Para o aprofundamento dessa questão ver: Foucault, M.A arqueologia do saber. Rio de Janeiro: Forense, 1997.
} 
Sendo assim, ao estabelecermos este trajeto, caminhamos por um veio pouco ortodoxo e convencional nas Ciências Sociais, tendo em vista que tanto a Análise de Discurso como as análises do cotidiano representam perspectivas que, sob o ponto de vista teórico-metodológico, abrem imensas possibilidades para novas questões e debates. Algumas já explicitadas no corpo do presente texto, apesar de não totalmente resolvidas, a exemplo da relação entre linguagem, história, discurso, ideologia e cotidiano. Diante das muitas dificuldades e de tantas incertezas, é imperioso que se estabeleça uma escuta sobre os "rumores", o que se passa realmente "em baixo", nos espaços muitas vezes silenciosos dos sentidos "ordinários" da vida cotidiana. Segundo Pêcheux, essa opção significa aproximar as "práticas da análise da linguagem ordinária" e as "práticas de leitura de arranjos discursivo-textuais". Segundo o autor,

Encarada seriamente (isto é, de outro modo que apenas uma simples "troca cultural") essa aproximação engaja concretamente maneiras de trabalhar sobre materialidades discursivas, implicadas em rituais ideológicos, nos discursos filosóficos, em enunciados políticos, nas formas culturais e estéticas, através de suas relações com o cotidiano, com o ordinário do sentido. Esse projeto só pode tomar consistência se ele permanecer prudentemente distanciado de qualquer ciência régia presente ou futura (quer se trate de positivismos ou de ontologias marxistas). ${ }^{41}$

Recebido em setembro de 2004.

${ }^{41}$ Pécheux, M. O Discurso: estrutura ou acontecimento. Campinas: Pontes, 1997. p. 49. 